\title{
Design of Monitoring and Control System for Indoor Flammable Gas
}

\author{
Zhao Rongrongi, 2, a , Ma Ling $^{1,2, b}$, Wei Hongmei ${ }^{1,2, ~ c}$, Pang Guoguang ${ }^{1, d}$ \\ ${ }^{1}$ School of Mechanical Engineering, Shandong Huayu University of Technology, Dezhou 253034, China \\ ${ }^{2}$ Dezhou Municipal Key Laboratory of Industrial Robot Control, Dezhou 253034, China \\ a qihezhaorongrong@163.com, b534695065@qq.com, ${ }^{\text {c } 37360715 @ q q . c o m, ~ d p g g 366123 @ 163 . c o m ~}$
}

Keywords: indoor environmental quality, flammable gas, detection and control

\begin{abstract}
Indoor environmental quality (IEQ) is very important for people's health, and the leakage of natural gas and chemical gas in the application seriously affects the IEQ and threatens human life and property safety. Aiming at the potential safety hazard caused by flammable gas leakage, a real-time monitoring and control system, controlled by sensor and the short message module of global mobile communication system for flammable gas detection and emission, is designed, which ensures the safety of people's life and property. Experiments show that the monitoring and control system has advantages of highly intelligent, stable and reliable.
\end{abstract}

\section{Introduction}

With the development of science and technology, people's living standards are greatly improved [1]. In life and production, natural gas and chemical gas provide great convenience for people, and can be widely applied, but also bring significant security risks. According to the National Bureau of statistics, in 2016, up to more than 750 events are triggered by natural gas leak, bring serious the loss of lives and property [2]. Therefore, it is urgent to detect and control flammable gas leakage quickly and accurately. At present, the indoor flammable gas detection alarming device only when gas concentration reaches the alarm limit, it uses the acoustic-optic alarm to prompt the staff to take measures, and the alarm device itself does not start the function of the exhaust fan [3]. In order to meet the needs of intelligent products and ensure the security of people's lives and property, a detection control system, which controlled by sensor and GSM module, is designed in the paper. The system can greatly reduce the explosion and poisoning incidents caused by flammable gas, reduce the occurrence of safety accidents, and ensure the security of people's lives and property.

\section{Structure and Working Principle of the System}

\subsection{Structure}

The monitoring and control device is mainly composed of gas sensor, single chip microcomputer (SCM), fan, motor, GSM module, electromagnetic valve, frame and so on. The device structure is shown in Figure 1. The gas sensor detects whether the indoor gas safety indicator is normal and sends electrical signals to SCM. The single chip microcomputer controls the opening and closing of the frame, electromagnetic valve and exhaust fan by receiving the electrical signal transmitted by the gas sensor. The electromagnetic valve realizes the opening and closing of the leakage source pipeline by receiving the control signal of SCM. The electric motor receives the control signal of the SCM and uses the chain drive to realize the opening and closing of the window. The limit switch controls the stop position of the form. GSM-SM modem can transmit the warning information by receiving the control signal of SCM. 


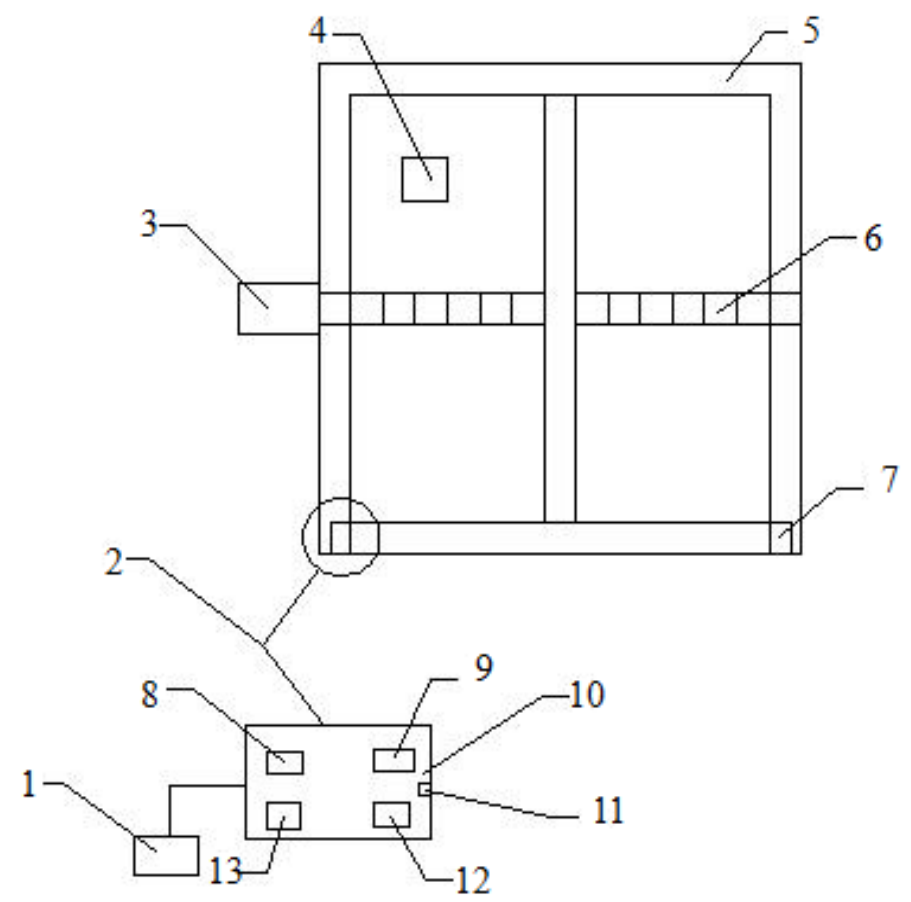

1. electromagnetic valve 2. control panel 3. motor 4. exhaust fan 5. frame 6. transmission chain 7. travel switch 8. SCM 9. motor drive module 10. control panel 11. power supply 12. gas sensor 13. GSM module

Figure 1 Physical structure of the system

\subsection{Working Principle}

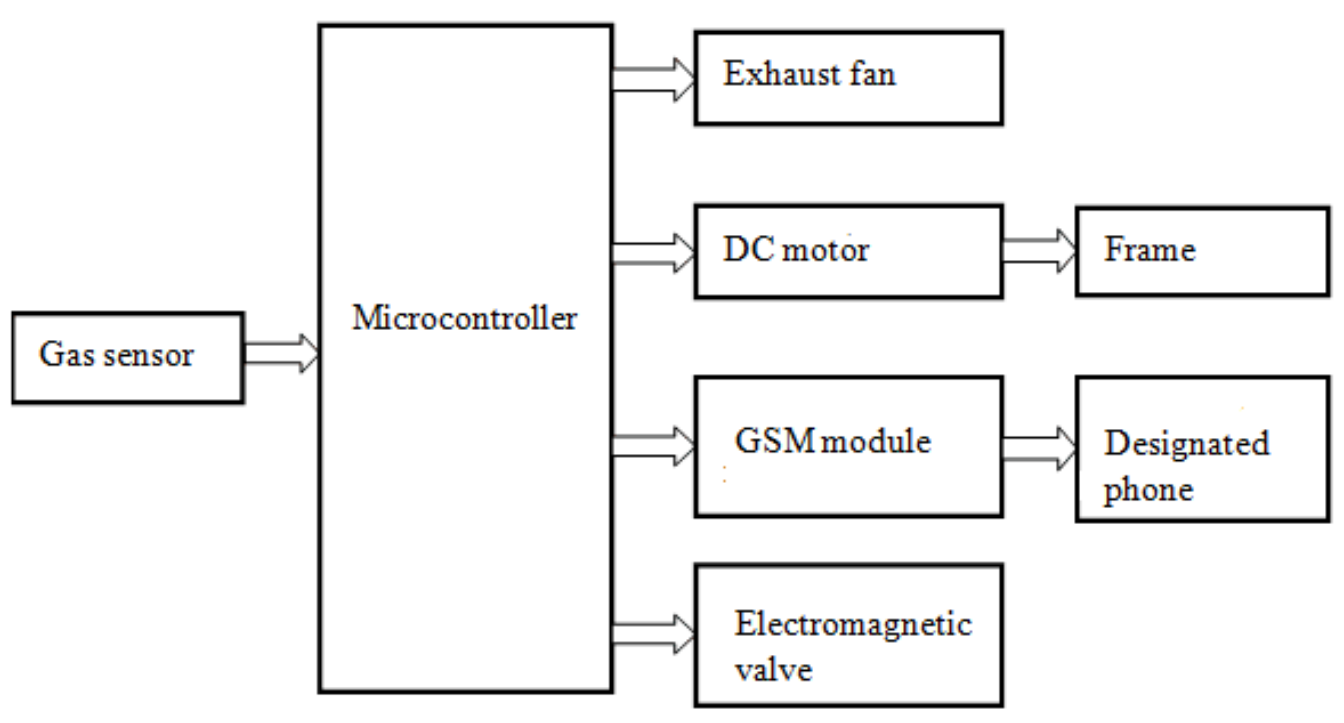

Figure 2 Schematic diagram of the system

The automatic monitoring and control device uses technologies of combustible gas automatic detection, signal transmission and conversion, motor and electromagnetic valve remote control, GSM alarm information transmission, to achieve indoor automatic detection and emission of flammable gas[3][4].When the sensor detects indoor flammable gas leakage, the electrical signal is sent to the SCM, and the SCM controls the solenoid valve of the natural gas pipeline to close at the first time to stop the leakage source. At the same time, the SCM sends the signal to control the rotation of the DC motor that drives the transmission device to open the window and exhaust fan. The combustible gas is discharged from the room and the alarm message is sent to the designated cell phone through the GSM-SM modem. When the indoor gas is restored to normal, the SCM sends the signal to control the DC motor to close the window and stop the exhaust fan to run, and 
the information of danger elimination is sent to the user cell phone through the GSM-SM modem [5][6]. The schematic diagram is shown in Figure 2, and the control circuit is shown in Figure 3.

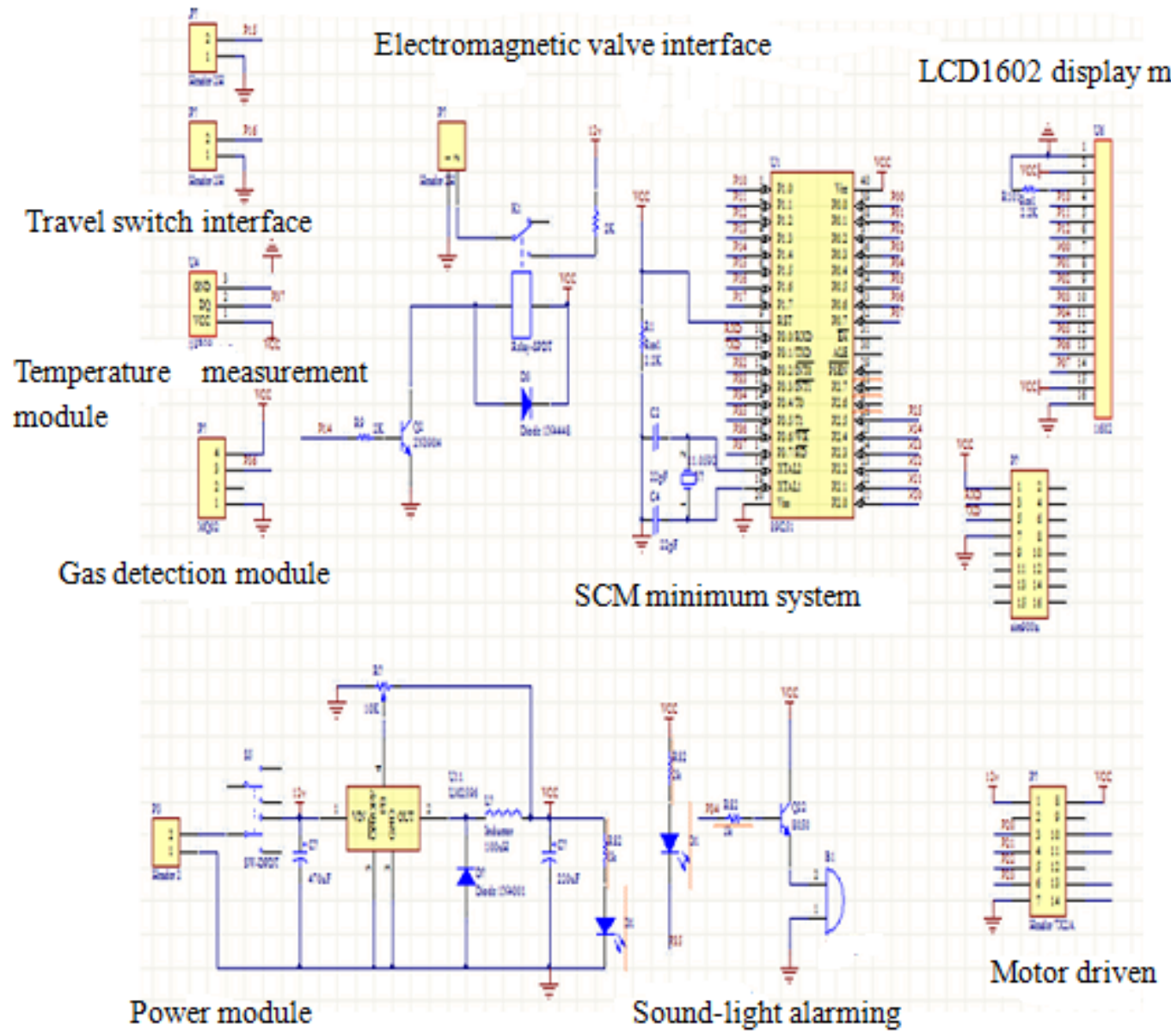

Figure 3 Control circuit

\section{Performance Parameters of System}

The following optimum parameters are obtained by a large number of experiments.

(1) Detection of flammable gases such as methane and butane.

(2) Alarm concentration 2\% LEL 6\% LEL.

(3) Power supply AC220V $\pm 15 \%, 50 / 60 \mathrm{HZ}$.

(4) Power consumption $\leq 3 \mathrm{~W}$.

(5) Sound-light alarming system (alarm volume $\geq 70 \mathrm{~dB}$ ).

(6) Ambient temperature $0^{\circ} \mathrm{C}-55^{\circ} \mathrm{C}$, relative humidity $\leq 95 \%$.

\section{Conclusions}

A monitoring and control system for automatic detection and information transmission of combustible gas is designed in this paper. The monitoring and control system is made up of gas sensor, GSM module, and micro-controller and so on. Tests prove that the monitoring and control system is stable and reliable.

\section{References}

[1] Jiang S. M., Hu Y., Liang J. (1999) Design of Detection and Alarm System for Flammable Gas Controlled by SCM. Heilongjiang Electronic Technology, 4, 15-16.

[2] Liu D. L, (2011) The Design of Flammable/Toxic Gas Detection Alert Control System. 
Automation in Petro-chemical Industry, 3, 39.

[3] Wang L. Z. Feng Z. H., etc. (2007) Activating Ventilation Control System on Inflammable Gas Detecting and alarming. Industrial Safety and Environmental Protection, 8, 39-40.

[4] He L. M., (2016) SCM Advanced Course of Application and Design (Second Edition) [M]. Beihang University Press.

[5] Zhou H. C., (2015) Single Chip Microcomputer Application Programming Technology (Revised Edition) [M]. Beihang University Press.

[6] Li H., (2012) MCS-51 Series Microcontroller Using Interface Technology [M]. Beihang University Press. 